University of Wollongong

Research Online

Faculty of Social Sciences - Papers (Archive) Faculty of Arts, Social Sciences \& Humanities

2018

Ethnic diversity, scarcity and drinking water: a provocation to rethink provisioning metropolitan mains water

Gordon R. Waitt

University of Wollongong, gwaitt@uow.edu.au

Follow this and additional works at: https://ro.uow.edu.au/sspapers

Part of the Education Commons, and the Social and Behavioral Sciences Commons

Research Online is the open access institutional repository for the University of Wollongong. For further information contact the UOW Library: research-pubs@uow.edu.au 


\title{
Ethnic diversity, scarcity and drinking water: a provocation to rethink provisioning metropolitan mains water
}

\author{
Abstract \\ Urban water scarcity in south-east Australia forces us to engage with how our present centralised public \\ utilities are embedded in our everyday lives, amidst uncertain futures. In the last decades, socio-technical \\ approaches have illustrated how the myth of endless main water supply is made possible by cultures of \\ engineering and plumbing. To extend debates about the cultural dimensions of environmental \\ sustainability, this paper takes an ethnographic approach to understand the processes by which Burmese \\ refugees and migrants who lived with water scarcity pre-migration make water potable post-migration to \\ Australia. With a focus on mapping the material, discursive, spatial and emotional relations that enable \\ the provisioning of potable water, the paper brings into conversation Elizabeth Shove's social practice \\ theory with Elspeth Probyn's emplaced formulation of subjectivity. The adaptive provisioning capacities of \\ people whose lives are immersed in cultures of water scarcity point towards a politics and relational \\ ethics of care underpinned by provisioning and first-person contact. To conclude, these grounded \\ Burmese examples provide an opportunity to employ scenario thinking to imagine alternative drinking \\ water futures for south-east Australian cities.

\section{Disciplines} \\ Education | Social and Behavioral Sciences

\section{Publication Details} \\ Waitt, G. (2018). Ethnic diversity, scarcity and drinking water: a provocation to rethink provisioning \\ metropolitan mains water. Australian Geographer, 49 (2), 273-290.
}


Ethnic diversity, scarcity and drinking water: a provocation to rethink provisioning metropolitan mains water

\title{
Gordon Waitt
}

School of Geography and Sustainable Communities

University of Wollongong, New South Wales, 2522

\author{
Australia \\ gwaitt@uow.edu.au
}

\section{Acknowledgment}

I thank the research assistance of Louisa Welland, the cultural liaison assistants (Min and Mya), the study participants, the two anonymous referees, Chris Gibson, the editor of Australian Geographer and the staff and higher degree research students at the University of Wollongong and beyond that provided helpful feedback on earlier versions of this paper including Lesley Head, Leah Gibbs, Heather Goodall, Natascha Klocker, Rebecca Campbell, Anath Gopal and Ryan Frazer. I am indebted to their generosity. The authors received financial support for the research from the Australian Research Council Discover Project, DPI40I0I I65 Sustainability and climate change adaptation: Unlocking the potential of ethnic diversity 


\title{
Ethnic diversity, scarcity and drinking water: a provocation to rethink provisioning metropolitan mains water
}

\begin{abstract}
Urban water scarcity in South East Australia forces us to engage with how our present centralised public utilities are embedded in our everyday lives, alongside its uncertain futures. In the last decades, well-rehearsed in the literature are the challenges of sustainable mains water supply made possible by cultures of engineering and plumbing. To extend debates about the cultural dimensions of environmental sustainability this paper takes an ethnographic approach to explore Burmese' refugees and migrants who lived with water scarcity pre-migration to Australia. With a focus on mapping the material, discursive, spatial and emotional relations that enable the provisioning of potable water, the paper brings into conversation Elizabeth Shove's social practice theory with Elspeth Probyn's emplaced formulation of subjectivity. The adaptive provisioning capacities of people whose lives are immersed in cultures of water scarcity point towards a politics and relational ethics of care underpinned by provisioning and first-person contact. To conclude, these grounded Burmese examples provide an opportunity to employ scenario thinking to imagine alternative drinking water futures for South East Australian cities.
\end{abstract}

\section{Keywords}

Social practice theory, cultures of urban water, ethnography, Burmese, politics of care

\footnotetext{
${ }^{1}$ In 1989, the military government of the Union of Burma changed the official name to the Union of Myanmar to better reflect the ethnic diversity and sever the State from its British colonial past. The United Nations accepted the name change, although those opposed to the military government questioned the imposed changes. At the same time, many of place names were changed from English to conform with Burmese spelling, for example Rangoon to Yangon. Mindful that the act of naming is always political, this paper reflects the participants' use of the terms 'Burmese', 'Burma' and English place names.
} 


\section{Introduction}

Plumwood (2007) calls for us living in the Global North to farewell our modern selves born of the Enlightenment who live with the western ideals of progress, freedom, reason, rationality and control over a 'dead' nature and imagine ourselves anew. Plumwood's (2007, I) perspective of the modern subject provides important insights here: '[T] he time of Homo reflectus, the self-critical and self-revising one, has surely come. Homo faber, the thoughtless tinkerer, is clearly not going to make it. We will go onwards in a different mode of humanity, or not at all.' Like Gibson-Graham and Roelvink (2009) I ask: What range of characteristics would contribute to a 'different mode of humanity' (Plumwood 2002) that can be enrolled here and now? In answering this question, I turn to first-generation Burmese migrants living in metropolitan Sydney. After Head and Gibson (20I2) these migrants past endurances and lived experiences of drought provide possibilities to think everyday life differently. In doing so, I follow the lead of Maller (20II) and Klocker and Head (20I3) who suggest that strategies for rethinking sustainable cities and becoming differently modern could glean important insights from the cultural capacities of diverse migrants.

In the context of a drying climate in South East Australia, the aim of this article is to ask: what principles might be learnt from Burmese first-generation migrants that grew-up with regimes of water scarcity to imagine a more sustainable urban water future? The need for critical perspective into where our mains drinking water comes from, was made evident by the severity of droughts in the first decade of the 2000s (Head et al. 20I4). Household water restrictions imposed during the 'Big Dry' or 'Millennium Drought' provided tangible evidence of limits to the existing mains water infrastructure that was built for Australian cities at the end of the nineteenth century and retrofitted in the twentieth century (Davison 
2008, Moy 2012). Water intended for drinking is supplied to households in Australian cities by kilometres of pipes from treatment plants and distant reservoirs is understood an inalienable right. Yet, this socio-technical system often goes unnoticed - that is until an algae bloom, media reports of a harmful chemical substance or a drought. Indeed, for most of us, mains water that is vital to our lives is devoid of any personal attachment. In the context of continued rapid population growth and a changing (drying) climate in South East Australia, the question of how to continue to supply mains drinking water gains increased political traction (Dovers 2008). The challenge of sustainable water management is being met with multiple responses. Some envision a secure future for drinking water in Australian cities guaranteed through public-private partnerships that generate new supplies - as evidenced by the recent state government investments into desalinisation plants in Adelaide, Brisbane, Melbourne, Perth and Sydney (see Spearritt 2008 for a discussion of South East Queensland). In such cases, water scarcity cemented the power of capital intensive technology with little concern for sustainability. Others, despite evidence of awareness of knowledge not being a good predictor of behaviour change (Lam 1999), envision the household as a site of education, focussing on individual use of taps, toilets and timing showers. And yet others explore whole-of-lifecycle economic considerations and watersensitive urban design (Syme 2008). Here, I offer an alternative fertile theoretical perspective at the intersection between practice-based accounts of social change and placebased accounts of subjectivity to the challenge of provisioning drinking water to the millions of people living in Australian cities. To do so, I offer a performative account of the drinking water practice geographies of Burmese migrants living in Australia who grew up with regimes of water scarcity in their pre-migration contexts. 
The argument is structured as follows. First, I briefly outline how socioeconomic and sociotechnical perspectives offer contributions to help understand and find solutions to the water 'crisis' facing South East Australian cities. Next, to champion the 'here and now' and lived experiences, I bring Shove's (2003) social practice theory into conversation with Probyn's (2003) performative ontological subject. I offer a performative account of the drinking water practice geographies to explain how provisioning water that is categorised as potable is a practice of care. Third, I outline my ethnographic approach that combined cultural liaison assistants, semi-structured interviews and home-insights from inviting participants to show us where, how and when water is used, alongside the material and sensory components of its consumption. I then map emergent subjectivities that arise within the sociotechnical water systems beyond and within metropolitan centres of Burma that provision drinking water. Participants' water narratives embraced a singular value of water; it was defined as essential to life. By espousing a value indicative of a politics of care that is indicative of a commitment to water and social justice, attention then turns to how this value contributes to, and is part of socio-technical water systems and carer subjectivities. To conclude, I argue that culturally diverse perspectives and a theoretical framework of drinking water geographies that better understands the complexities of the processes that make water potable provides a provocation to pose a scenario that may help imagine alternative pathways for more sustainable south-eastern Australian urban water futures.

\section{Cultures of urban water}

Secure supply of safe drinking water is frequently described as a 'crisis' for south-eastern Australian cities. This challenge is often presented in government reports in terms of predicting supply and demand, underpinned by an understanding of mains drinking water as measurable entity. As Alon and Sofoulis $(2006,46)$ argue, 'effective management of water demand cannot ignore the social and cultural differences associated with different habits, 
expectations, meanings and practices of water use'. Cultural approaches shifted the debate from metric units consumed to what water makes possible. Research on urban water cultures is characterised by two key approaches; socioeconomic natures and sociotechnical systems.

The socioeconomic natures perspective offers a theoretical understanding that encompasses a political ecology framework of mains drinking water that stresses the ways water evades capitalist control. As Bakker (2004, 33) suggests, water is an 'uncooperative commodity', primarily due to transport costs. Political ecology revealed the processes whereby state institutions took responsibility for the supply and quality of mains water. The historical emergence of accepted categories of mains water quality was tied to the western myth of progress and modernisation as a means of social advancement by addressing the medical risks related to drinking water. Indeed, until 1994, Australian plumbing standards forbade rainwater tanks from being connected to pipes used by utilities to supply mains drinking water. Since 2015, the New South Wales (NSW) Building Sustainability Index requires every new build to install an alternative water supply to the mains. That said, regulation stipulate that backflow devices must be installed to prevent rainwater from entering the mains supply. This is because rainwater based on Australian Building Standards (Leslie and Potter 2004) is categorised as water that drains from non-trafficable roof areas of a building structure. Hence, the web-page of the NSW Department of Primary Industries (2017) supports the use of rainwater for toilet flushing, hot water systems, garden watering, car washing, swimming polls and washing clothes. In contrast, echoing the NSW Health (20I7) guidelines, the NSW DPI continues to inform readers that: 'The use of rainwater tanks for drinking purposes is not recommended where a reticulated potable water supply is available'. Furthermore, committed to discursive analysis of socioeconomic natures, urban political ecologists identified how the modern city and home became seemingly independent 
from nature, although reliant upon controlled flows of water. This reflects political ecology's dominant mode of explanation. The city is understood as an expression of the relationships of capitalist economies and draws on nature-culture dualisms that construct city spaces as devoid of nature or, at best, of tamed nature (Gandy 2002; Kaika 2005).

In capitalist societies, massive investment is required to transcend the medical risks of water-borne disease through dams, reservoirs, pumping stations and pipes. Political ecology challenges taken for granted concepts such as 'water quality', 'purity', 'freshness' and 'potable water' by drawing attention to how powerful institutions (such as water utilities and government departments) normalise these terms. Households develop demands and expectations about drinking water that are 'invented' and 'imposed'. At the same time, political ecology advances the notion of 'hybrid' to argue that the seemingly unnatural is full of nonhuman life and agency. As Head and Muir (2007) show in the case of Australian backyards, plants shape experiences and meanings of water, homes and gardens through an array of routines and rules related to 'plantiness'. They argue that the quality of shower water is transformed at times of drought. As evidence, they point to backyard gardeners' responses to encounters with wilted plants as an instance of 'culture change', because they collected water in a bucket while showering. In sum, a political ecology approach is an antiessentialist project that challenges taken-for granted categories like mains, rain and tank water and points towards the governmental control over mains drinking water within a capitalist market. Explanations for everyday mains drinking water experiences in cities, following the logic of political ecology, can be found in the ways that governments respond to the uncooperative attributes of water inherent in a capitalist economy.

After Bijker \& Law $(1992,13)$, sociotechnical perspectives include both human and nonhuman elements that are 'bound together in networks [and] are at the same time, constituted and shaped in those networks'. From a sociotechnical perspective, explanations 
turn to how the material affordances of technologies and things become integrated into stabilising and transforming everyday routines and activities. For example, Sofoulis (2005, 2006, 20I I) and Lawrence and McManus (2008) provide illustration of how the technologies of centralised water-services provisions work against sustainability by delegating responsibility of water use to water utilities rather than households. As Sofoulis $(2005,455)$ writes, 'users are left with the remnant responsibilities of simply using this water to maintain desirable standards of cleanliness about their home and person, and keeping alive the nation-building Big Water dream in their backyard oasis'. As Sofoulis (2005) argues, the fantasy of endless water supply in Australian cities is maintained by the working arrangement of meters, bills, pipes and drains.

Here, I build on sociotechnical perspectives that encompass how place, people and things are co-constituted. The first analytical prism I engage understands the provision of potable water in through a theory of practice. After Shove et al. $(2012,7)$, individual and household practices are understood as a 'routinised type of behaviour' at a societal level rather than following socio-psychological theories of behaviour at the individual level. After Reckwitz (2002, 243-263), 'wants and emotions do not belong to individuals but - in the form of knowledge - to practices' and that 'a practice is thus a routinized way in which bodies are moved, objects are handled, subjects are treated, things are described and the world is understood'. Following Reckwitz (2002), for Shove et al. (2012) practices become durable via the relations between 'materials', 'competencies', and 'meanings'. Materials 'include things, technologies, tangible physical entities and the stuff of which objects are made' (Shove et al. 2012, 9). The materiality of things is understood as actively involved in the making and remaking of routines and spaces through enabling agencies and competencies. Competencies refer to 'skill, know-how and technique' (Shove et al. 2012, I4); and meanings to 'symbolic meanings, ideas and aspirations' (Shove et al. 2012, 14). The value of Shove et 
al.'s (2012) approach is that it provides a blueprint for a creative diversity of practices that are continually reproduced and reinvented through the ongoing everyday interactions between materials, competencies and meanings. Practices are understood to change when the connections between these elements are somehow modified. Through this prism of practice, we can understand how provisioning water intended for drinking is the outcome of many material and technical elements (reservoirs, wells, taps, tanks, pipes, pots, fridges, bottles); bodily competencies that enable water to be carried, stored and decontaminated; alongside knowledge about water borne diseases and what constitutes potable water. Thus, we might begin to trace how a broad array of social and material elements work together to create a diversity of drinking water possibilities.

My second analytical entry point is through a spatial theory of subjectivity. Like the feminist Butler (1993), Probyn (2003) rejects the idea that identities are fixed. Instead, Probyn (2003) advocates for a performative ontology of the subject that positions the productive aspect of language in a wider relational framework that includes the social (ideas, ideologies, emotions) alongside the material (bodies, technologies and things) (see Waitt and Warren 2008, Waitt and Clifton 2013). Such a theory of subjectivity suggests a notion of 'situatedness'; whereby how people and place are mutually constituted, shaped and reshaped through the relatedness of ideas, things (including water), emotions and affects. Probyn $(2003,290)$ inspires us to think about the "spatial imperative of subjectivity". The important point is that subjectivities are given stability through the performative force of the provisional working arrangement of social and material elements. This invites us to consider the spatial contingencies of subjectivities that emerge through the provisioning of water understood as potable. This spatial understanding of subjectivities as emergent, dialogic process of place, reminds us that the challenges of water shortages and responses to them have much to do with the ways water is used to make and unmake social categories. The 
stopping, changes and continuation of everyday drinking water practices is conceived in relationship to the subjectivities, social norms, material, bodily experiences and skills of living in a specific place. Hence, rather than drinking water being made meaningful within a structural explanation of production, distribution and retail; a drinking water practice geographies framework invites us to map the ways which water becomes potable through dynamic and unpredictable relationships between social and material entities.

\section{Methodologies}

To research how water is made and experienced as drinkable this paper draws on the accounts of 16 first-generation Burmese refugees and migrants living in metropolitan Sydney who consented to take part in a project about domestic water. Since 2010, Burma has been one of the largest source countries of new immigrants to Australia. In 2015 , there were approximately 23,500 registered Burma-born migrants in Australia. Approximately half were granted Australian permanent residence in the past five years, primarily through humanitarian visa programs (ABS 2016). Participants were recruited through two cultural liaison assistants. Mya is female, from Burma, and came to Australia as an asylum seeker in 20I4; and, Min is male, from Burma, and migrated to Australia on a student visa in 2014. Mindful of the advice of Falconer Al Hindi (1997) in conducting cross-cultural research, two Burmese cultural liaison assistants aided the project design, protocol, delivery and coproduction of knowledge. Semi-structured interviews and collaborative home tours provided a route to knowledge via collaborative and reflexive research encounters, between participants, cultural liaisons, researcher, objects and place.

The research occurred in January-February 2015. All participants spoke some English, but Burmese was normally the main language spoken at home. Only four had lived in Australia for more than five years. Six participants were men, ten were women. Within the sample 
there was diversity of socio-economic status, migrant histories, ages, religious beliefs, employment and ethnicities. Six participants are refugees. Ten migrated with either a student, family or skilled migration visa. They ranged in age from mid-20 to early 70 s. Nine claimed a Burmese ethnic nationality, three a Chin, two a Karen, two a Shan and only one a Chinese-Burmese ethnic nationality. Four of the participants were full-time students, three were full-time mothers and one worked part-time. Six were in full-time paid employment, and two were retired.

Participants were invited to take part in both a semi-structured interview and home insight. Five participants accepted our invitation to both phases. Eleven participated only in the semi-structured interview titled 'Talking Water'. The semi-structured comprised 7 sections: getting to know you, drinking water, washing-up, bathing, laundry, toilets and gardening. Each interview began with a conversation about the participant's migration history, and their understanding of water. Questions in each following section were designed to enable participants to compare practices between Burma and Australia. Semi-structured interviews were conducted in both Burmese and English. They allowed an entry point to understand everyday practices (Hitchings 2012) and to tell water life narratives (Riley and Harvey 2007). The home tours were led by participants but structured to provide insights around what water makes possible. To learn more about the embodied and emplaced feelings of domestic water encounters, participants were asked to show their usual domestic routines and activities that involved water. The purpose of the home tours was to supplement interviews using the meanings, feelings, material and sensory dimensions of water itself as a prompt and prop to facilitate the performance of water-based practices and subject positions.

All participants' narrative attached profound significance to water using work like 'important' 'crucial' and 'basic need'. For example, Mynit is a married woman aged in her 
forties who migrated to Australia in 2010 on a family reunion visa and spoke of a relatively affluent family background living in Rangoon. In her words, 'water essentially is life'.

Provisioning drinking water was central to demonstrating their capacity to care for water and its others. For this article, transcripts from interviews and home insights were coded to reflect how this value contributed to, and became part of socio-technical water systems in Burma. Subsequently, the analysis focussed on how particular understandings of drinking water became meaningful through mapping the intersections and connections between the ‘subjectivities', 'materials', 'competencies', 'meanings' and 'emplacement'. In doing so, I suggest how provisioning drinking water is enshrined in subjectivities that mobilise a politics and relational ethics of care that encourages mutual interdependence and discourages waste; two key features of a sustainable socio-technical water system.

\section{Mapping the socio-technical drinking water system beyond metropolitan centres}

\section{in Burma}

What are the drinking water geographies of those relatively socio-economic disadvantaged participants who previously lived beyond metropolitan centres in Burma? For these participants, being able to drink stream/well water is in part a product of the mediation of materials including clay, bamboo, pine and sand. The unpaid work of collecting drinking water, which is primarily conducted by women and younger children, brings to the fore interdependence and care. Many of the women involved in this study described their experiences of collecting water. Water was collected daily on-foot, and the women involved are 'emplaced' in the environment, and they deal with the weather, sunshine, heat, rain, and drought. For these women, water intended for drinking from streams or wells is tightly tied to gendered identifications, economies and subjective performances as carers and mothers. 
Performing care through the competencies involved in collecting and carrying well/stream water intended for drinking each day, sometimes twice a day, regardless of the distance, was felt as hard work. Khin is a young woman who was granted asylum in Australia in 20I3, having been forced to migrate from Chin State to Malaysia because of teaching Christianity. She explains the labour involved:

So, we have to carry water, it doesn't come automatically to our house ... we have to, it's very difficult to get water, some people get up early in the morning to get water because a lot of people, they want to carry water, there is a stream so every person has to get water from the small stream, so it is difficult. And, try to save water, yes, as it is difficult to get you know, water.

Similarly, Similarly Rudy, who like Khin is young women and Christian asylum seeker from

Chin State living here since 2013 - explained that in her village:

We have [a] well. So, we have to go to the well and they have to pour water like that. And then they fill up in container and so they have to carry. Before, yes it was a bit far, one furlong. It's a bit far from the home to the well. But they moved to, there is a church so they make one well, so it's very close.

Likewise, April is a young Chan-Chinese-Burmese woman who entered Australia on a student visa in 2013. April talked about the everyday routine and competencies of collecting drinking water daily as 'a lot of hard work' from having lived in a rural village in Kachin State. That said; collecting and transporting water to drink was integral to performances of individual and collective identity embedded in care. As April explained:

Every day you have to collect water from the well. Sometimes the summer came, sometimes in summer, because there's less water in the well, so we don't have enough water, we have to go to river to wash our clothes. It still has a little water, enough for drinking. But, you don't want to waste it on washing. Later you have nothing to drink.

The physical labour of performing care and mutual aid by walking, collecting and transporting water to drink, sometimes twice-a-day, made these women aware of, and sensitive to, the environment, distances, weather, changing seasons alongside the changing attributes of stream water (colour and texture) and flow. For example, some participants 
spoke about the sociotechnical stream-water system as potable, unless an animal strayed. For example, Khin explained that the stream is "very clean, unless someone put dirty things. So, if the animal goes and drinks then yes maybe dirty, otherwise it is very clean." Through first person contact these participants held a fine-grained sensitivity to care for the stream water as part of a shared 'commons' to create community well-being and health. Notably, these participants spoke of how the practices around the provisional social and material arrangements of Australian mains water provision made the subject feel like a 'waster'. In April's words:

Because now [in Australia] you can get [water] whenever you want, it's easy and you can, you know, I might waste some water now. But, back in the day, it's [water] very valuable because you have to get it. ... A lot of hard work so you are not going to waste any of the water, you use it very wisely. Now I might waste a little bit. April conveys some of the guilt of giving in to the comfort, convenience and seeming abundance of the sociotechnical system that constitute tap-water in Australia. As argued by Sofoulis (2005) and Lawrence and McManus (2008) the infrastructure of water supply in Sydney works against sustainable modes of operation. A key finding here is that the physical effort involved in caring for self and others alongside the intimate embodied knowledge gained through the daily provisioning of water to drink from a stream or well accentuates ethical considerations for water and community.

Furthermore, these women challenged western, capital-centric discourses of fresh potable water. For example, Rudy spoke about drinking water from streams to quench her thirst, without refrigerators or boiling. In her words; “In our village we don't have fridge, so when we want to farm, it is very hot and we are very thirsty so we just scoop the water and just drink it." Sui is a young mother of four children who identified as a Christian Chin, and was granted asylum in Australia in 2009. - said: "Normally, in Chin State we just drink fresh water, from the stream. We boil for my father because my father has gastric problems. We 
don't use filter in my village, we just drink fresh water." Usually, only those who had parents with weak immune systems took-up the practice of boiling and filtering drinking water using a cloth made of cotton as a strainer. The social and material entities that make stream water drinkable offers a different understanding of freshness from that entangled with the capitalist logic and proliferation of household refrigerators.

Indeed, the materiality of storage containers - clay pots, cloth, sand and boxes made of pine wood - was central to cultivating carer subjectivities in the provisioning of 'fresh' drinking water beyond metropolitan centres in Burma. According to participants, these materials were selected to keep water cool for drinking. Storage of cool drinking water became doable because of how the thermal dynamics of these materials intermingle with daily routines and competencies. As Rudy explained:

In Chin State we use, like pine tree as a container to make cool water. But, in my village, we don't have pine tree so what we did, we have clay pot and then under the clay we put sand. Sand in a container, there is a container so they put sand, on the top of sand they put clay pot and then that clay pot they wrap with cloths. So, in order to make water cool they spray or sprinkle they clothes with water. So, the clothes, they wrap the clay pot with clothes, right, so the wet clothes make the water cool.

Likewise, Kyi Kyi recalled through the cultural liaison assistant that:

We put the clay pot on the sand. We have a sand base. And then on the sand we put a clay pot and then inside the clay pot we put the water. And that water is very cold, like chilled water. Yes. So, what they do is they put the sand, lots of sand; and, on top they put a clay pot.

Kyi Kyi is a mature age Burmese grandmother who lived in Rangoon until six months prior to the interview. For these participants, an earthen pot was necessary to care for self and others by provisioning cooler drinking water in summer. The clay pot, wrapped with cloth, reduced the stored water temperature because of how water seeps through the pores of the container, and the latent heat of evaporation is taken from the pot and stored water, resulting in the cooling of the water. Likewise, water evaporating from the greater surface area created by both the cloth in which the clay pot is wrapped and the sand on which the 
clay pot is standing again helps the amount of evaporation occurring and prevents heat absorption. Therefore, the water that is stored in the clay pot is kept relatively cold. Furthermore, as Permetoe reminds us, clay pots must be well-maintained to keep water potable.

We clean the clay pot twice a day because it's dirty. Water is quite dirty so if we don't clean the water-- the bottom of the pot it dirty like mould; so, we have to clean.

Pemratoe is a young Karen women and Buddhist who entered Australia on a family reunion visa in 20I4. Cleaning of clay is a performance of self, embedded in care. Other participants spoke of the role of wooden containers in cultivating carer subjectivities and collectives through provisioning water to be drunk over the course of the day. As Khin explained:

We have a wooden, a wooden, like a container. Yes, it's a wooden container, so we pour water in that container and cover with the wood. To keep cool yes, it's very nice.

Likewise, Sui spoke of the role of wooden storage containers in creating herself as a subject of a collective economy:

Yes. In Chin State we store water with wooden pine tree, wooden container, so it makes it really cool. ... All of us have the water from the stream. We have a big wooden container so in that container they collect water and so the neighbour, they came and collect water from that. Some people, they put small stones in the container, they say that the stone make water cooler.

The practice of keeping daily water supplies cooler during summer deployed the low thermal conductivity of wood, whose porosity allows evaporative cooling from water that seeps through. Adding stones of low porosity and thermal conductivity - like marble further worked against warming. In Chin State, the pine box, small marble stones together and bodily competencies served in producing a communal 'we' - that is as subjects of a communal economy - through practices that provision cool drinking water and reconstitute a sense of care and specialness of potable water. .

\section{Mapping the socio-technical drinking water system in Rangoon}


In Rangoon, a report prepared by Tokyo Engineering Consultants et al. (2014) described the issue of water supply in Rangoon as 'chronic'. The 150-year-old centralised water system is primarily a legacy of the British colonial era. It has only one pumping station, Yegu, with chlorine injection facilities. Although only an estimated 37 per cent of the city is supplied with potable water, there is still insufficient capacity, therefore restricted water supply (average 9 hours), low water pressure and high leakage ratio. As reported by an anonymous reporter (2009) for the New Mandala 'those who can't afford to pay for a privileged connection will increasingly be left to find water wherever they can, including by digging holes around junctions on pipes to catch leakages in buckets and bowls and if necessary, by vandalizing pipes'. Hence, each year there are fatalities from waterborne infectious diseases including viral hepatitis, cholera, typhoid and diarrhoea (Sakia et al. 20I3). Hence, participants spoke not only of their distrust in the failing centralised water supply system, but a range of other sources as essential to hydration including installing their own pumps to above ground tanks, private wells, well water, water vendors, public water-hydrants and bottled water.

Our participants positioned the drinking water geographies constituted by the state utility in Rangoon as unhealthily, insecure, unreliable and inadequate. Min Zaw is a young professional Burmese man who is applying for registration as medical doctor, having migrated from Rangoon to Australia on a marriage visa in 2013 . He explained the mains water supply in Rangoon in the following terms:

We've got the centralised system but I think it has been damaged for a long time, so all of we have the chlorination system but we can't trust it, that chlorination is sufficient, to drink from the tap water. 
Tin Mar is a middle-aged professional Burmese woman who migrated to Australia on a family reunion visa in 2007 having grown up in a relatively privileged family in various rural and regional centres, including Rangoon. Tin Mar said:

Cooking we use the tap-water. Because drinking we don't believe the quality of the water pipes, the water system. Rangoon, this city area, they going to supply water tanks from the government, the council, so the tap-water we use that for other things, not for drinking water. We don't use the tap-water for drinking.

The shared understanding among those participants who had lived in Rangoon was that the state utility was unable to supply adequate safe drinking water to meet the demands of the increasing urban population, particularly during the summer. For example, May is an older mother who lived in Rangoon until entering Australia on a family reunion visa over a decade before the time of interview. She explained the demise of mains water supply in Rangoon through the cultural liaison assistant:

So, she said, when she was born this Rangoon, the one she lived in, [...] they have a water pipeline through the council, from the government, but, when she was young the water pipeline is very good facility, very good service and the water is enough, she doesn't need to, they don't need to worry about anything. But, when she getting older, growing, the population is growing. So, on that time, especially in summer they have a shortage.

In a failing socio-technical water system, participants described a variety of sources in the interest of organising safe and secure drinking water to care for themselves and others. Some affluent participants spoke of the emergence of capitalist enterprises; and arranging home delivered 19-litre plastic bottles of drinking water by private bottling companies. For example, Chit is 21 years of age Burmese, grew-up within a relatively affluent and highly educated family in Rangoon and entered Australia on a student visa in 2013. . . He explained why his family started drinking bottled water and stopped drinking well water drawn from the grounds of his parents' home.

So, when the water bottles came we start buying the water bottles ...we drink bottled water and even though it's like clean, fresh, but a little bit chemicals. 
Likewise, Tin Mar noted:

In my country, we buy drinking water through the company, they going to sell big bowl. Because drinking we don't believe the quality of the water pipes, the water system. Before we use the boil, heater, and then save. But now we don't need to do that one because they are going to sell drinking pure water, so we use that one. Drink water they sell from the manufacture company. So now, we don't need to do that procedure and we just buy drinking water.

In relatively wealthier Rangoon households, the market economy became the solution to basic hydration. Chit and Tin Mar showed their allegiance to capitalist identities as workers and consumers. In their households while living in Burma, capitalism became the normal means of fulfilling care economies of hydration through the purchase of bottled-water usually sold in 19 litre polycarbonate bottles. In the words of Tin Mar, the positioning of bottled water in the Rangoon market is because of its 'purity'. As argued by the Hawkins and Race (20I I) for Bangkok, integral to the socio-technical system of bottled water was the perception of tap water as unsafe, alongside social distinction, convenience and taste of a modernised lifestyle. In Chit's words: "the poor people like if they don't buy [bottled water] [...] they just have to drink polluted not clean water and they can get diseases et cetera." Chit draws our attention to how most urban poor in Rangoon bear the burden of limited access to drinking water as evident in waterborne diseases (see Graham et al. 20I3 for a discussion of the politics of water in Mumbai). Chit illustrates the ways water becomes potable is always emplaced and how people (gender, class), things (reservoirs, pipes, bottles, taps, fridges, kettles, water), skills (carrying) and social norms (health, freshness) are part of place., In other relatively affluent households, on which I focus below, the ontological doubt about the supply and safety of tap water for hydration, resulted in water and women being entangled through relations of care in a labour-intensive domestic pursuit of boiling, cooling and storage.

In the context of concerns about both drinking water security and safety, the provision of drinking water in Rangoon could be understood as a human achievement. The participants 
told stories of the physical labour and bodily competencies involved in the process of boiling, filtering and chilling household drinking water in Rangoon. For example, Mynit provided a step-by step explanation, through the cultural liaison assistant, of how households cultivate subjectivities that care for self and families through a labour-intensive treatment process:

So, she, firstly, she take the water from the main pipe, then she boil it on the stove until it reaches boiling degree, then make it cool for like ten to fifteen minutes. Then they have fridge so put it in the fridge. Because it's hot there in summer time.

Careful boiling of water, container preparation and refrigeration ensured the water became and remained potable. Mynit was not alone in talking about performing subjectivities of care by these labour-intensive pursuits afforded refreshing chilled tap-water drinks. These practices made sense to participants due to health concerns of drinking tap water, primarily water-borne diseases. In the cultural liaison assistant's translation of Mynit's explanation of why she boils tap-water:

To kill, clean the water, to kill the germs. So that it's drinkable. She thinks that it's not safe to drink.

Similarly, Min Zaw explained:

Because of the diseases transported through the water, water borne... We also have to worry about that ... So, we just get the water from the tap and then we boil it and let it cool and then we drink. We have some container and some kind of bottles, yeah. The electricity broken most of the time so, yeah, but, we usually put the container in the fridge.

Like Mynit, Min Zaw was well versed in the nineteenth century scientific ideas of germ theory that established microbes as responsible for water-borne diseases (Sedlak 20I4).

The provisioning of safe drinking water supplied from the mains becomes do-able and gains a sense of specialness through the gendered relations between routines, competencies, technology and space.

Yet, the provisioning of drinking water is never simply a human achievement. Instead, participants spoke of learning about the materiality of water, through taste and sight. 
Through this embodied knowledge, the participant engaged with the materiality of water and modified their practices. For example, May's filter use, as explained by the cultural liaison assistant, illustrates how she learnt about provisioning potable water through observation.

She use a cloth and then put in the water and then filter and some of the dirts and some things going away, and then she drink it. She use the drink water from the tap water, from the tap, but she use the filter. [...] So, they use it like, the cloth is very thin and so the water is coming drop by themselves. Yeah, any black and something, because the white colour, you can see straight away and after that we have to wash it; and, then we use twice and then we can change it for a new one.

Thus, water emerges as active in the process of purification, her observations of water colour guiding May's practices. The processes of making water drinkable, can thus be understood as a responsive activity, in which participants became aware of the material qualities of water. Mynit provided the water with care through filtering practices, in turn, the water provided life for her family. This process is so entangled that the actions of water and people are working together to provide drinking water. Provisioning drinking water through this de-centralised socio-technical system felt special by drawing water and people into relations of care. On the one hand, carer subjectivities are performed through alleviating concerns about contamination of both chemicals and dirt. One the other hand, participants were committed to the care of water, by not wasting. Provisioning water is a home-making practice that is not only about maintaining a healthy body and carer subjectivities but maintaining an ethical interdependence with water.

Knowledge of this ethical interdependence with water became evident in participants' narratives about stopping or continuing practices of boiling and filtering water postmigration. For example, Min Zaw's household stopped boiling water since becoming entangled in the centralised socio-technical mains water system of Sydney: 
I just remind that, we don't need to boil it so it's saves a certain amount of money and another thing is that, the other drawback is that we can get [...] the water directly from the tap so we don't care how much the water waste: it's so convenient. So, that yeah. So, it's unlimited, yeah. So, sometimes we're careless.

Those like Min Zaw pick up on the messages and political 'scripts' built into infrastructure. He rationalised his new practice of drinking water direct from the Australian tap in terms of reducing his electricity bill, unlimited supply and convenience. He illustrates the role of water as a social actor according the Australian political 'script' that positions potable mains tap water as unlimited and a cultural script of flowing tap water as enabling modern lifestyles based on the notion of convenience. Moreover, Min Zaw demonstrates how the domestic water fittings in Sydney work against relations of care between people and water. How the things come together to forge domestic places sometimes encourages people to be 'careless'. Min Zaw is aware of his emergent subjectivity as a 'waster' constituted within the places, materials, skills and discourses of the domestic Australian mains water sociotechnical system. Likewise, Tin Mar explains:

So, in my country [Burma] water is very hard to get it and water quality and everything. But for me, [...] growing up in my country long time. So, [...] when I come here [Sydney], so water quality is [...] very good for this service. The quality is maintained and improved. So, in my country I don't believe the water tap, tap water, and here [Sydney] we do believe. And, we, there's no doubt for the water quality. But the thing is that here], the water is unlimited, we can use anytime in whatever you want to use. [...] I don't need to worry about any water supply. I don't need to worry about water well. Sometimes in here [Burma], water problem, they have water pipe broken or something, they will stop water supply two days, one day, something like that. Here, nothing.

Tin Mar illustrates how the water fittings enable water to appear as unlimited in her Australian home. The socio-technical system of Australian water provisioning that enables water to seemingly continually flow from urban taps privileges a historical fantasy of infinite supply and concerns for future water supply. As argued by Sofoulis (2005), the infrastructure supply of 'Big Water' released Tin Mar from responsibility from limiting domestic water consumption. Yet, as Tin Mar went on to explain, water use practices from 
childhood committed to the care for water as special and against excessive consumption of a seemingly unlimited resource of high quality.

But the thing is that here, the water is unlimited, we can use anytime in whatever you want to use. But the thing is, for me, this habit, it's still coming, I wash my rices and I still using for my garden. So that's the answer, just like habit and then, even unlimited water and water quality is very good, I don't need to think about the water supply, I don't need to worry about. But still, I am using this habit. Still practicing.

The embodied history of scarcity makes for a commitment to care for water by saving.

Likewise, Mynit explained through the cultural liaison her concern and emotional

commitment to care for water derived through boiling water to drink.

Yes, she's still worried because she's used to it for a long time [...] She's been here for only five years so she's still used to it. [...] But she feels like it's safer here compared to Burma, even though it is treated, maybe treated differently so safer here. But she still boils. Because her husband explained about the water, that it is quite clean here [...], so in the future she might just attempt the culture here but, until now she will still boil. She's quite adamant about it.

Mynit did not relinquish water boiling practices, despite efforts from her Burmese husband to vindicate drinking Australian tap-water as 'safer'. For Mynit, abandoning these drinking water provisioning routines following migration would mean giving up process through which a home and subjectivities as a wife and grandmother are constituted and experienced, including an ethics of interdependence. In her words: "Saving water is very crucial and even for drinking, yes, you should clean it thoroughly but don't waste at all, there's no point".

\section{Conclusions}

This project offers insights into the practices and subjectivities by which water becomes potable - amongst Burmese migrants who lived with water scarcity or uncertainty of both centralised and de-centralised socio-technical water systems pre-migration. To do so, it relied upon a collaborative research design with first-generation Burmese migrants living in Sydney, which involved working with first-generation Burmese migrants through cultural 
liaison assistants to secure personal stories related to domestic water. The approach adopted in this paper that brought practice-theory into conversation with performativity relies upon thinking about how subjectivities emerge through provisioning drinking water at the intersection of materials, competencies, and meanings. If provisioning water to drink is read as something that is performatively constituted, then drinking water becomes a site of decision making that must be actively achieved. Those whom have grown-up and lived with water scarcity of both decentralised and centralised socio-technical water systems highlight provisioning of water is entangled in subjectivities, politics and ethics of care.

How does this analysis highlight how the social and material worlds are entangled help shift western urban cultures of water into more sustainable future modes? First, the current 'water crisis' in South Eastern Australian cities cannot solely by attributed to a drying climate. Burmese migrant narratives bring to fore that what makes drinking water possible may be conceived as a socio-technical system that shifts attention to how subjectivities and responsibilities emerged within the provisional arrangements between emplacement as a primary condition of subjectivity, competencies (storing, filtering, boiling, pumping), meanings (cleanliness, purity, fresh, potable) and materials (water, water technologies). For the participants, practices of provisioning water to drink in Burma from wells, rivers and tanks involved generating an intimate connection through routines of collecting, boiling and filtering. Their stories demonstrated a well-entrenched ethic of not wasting 'hard-wired' into this de-centralised, small-scale socio-technical water system. Their water narratives again underscore arguments that neither technological fixes nor changing meanings alone will not work towards more sustainable futures (Sofoulis 2005; Moy 20I2, Head et al. 20I3; Gibson et al. 2013). Instead, progress towards more sustainable water futures requires change across the competencies, meanings and material. 
Second, clear illustration is given to the politics of care; that is how and why participants care for themselves and others by the work of provisioning water. Public utilities that provision water illustrate a politic of care for citizens. Participants understand access to mains drinking water is the ultimate index of a state's capacity to care for its citizens because water is quintessential to human health. The challenge of a centralised sociotechnical system is that domestic water practices often become unsustainable because the social and material elements pass responsibility for water onto the service provider.

Having migrated to Australia with domestic water practices of saving; living with centralised large-sale socio-technical water systems, these participants articulated a sense of guilt associated with becoming a water 'waster' by letting mains drinking water flow - even if just for extra seconds. For those participants who had previously lived with the scarcity of stream/well water and tap water, the practice of provisioning water was linked to a felt interdependence and guiding ethic of care. The practices of everyday water consumption of Burmese migrants are aligned with an emotional commitment for saving water, alongside a responsibility to care for community and kin well-being. These embodied engagements are inextricably linked to home-making, performances of self and where an ethics of interdependence is acknowledged. The Burmese participants in this study challenge us to think about what it means to live as part of diverse interconnections in which water becomes not only drinkable but involves a politics of care for water and its others.

Can we imagine a future urban Australia where individuals are charged with greater emotional commitment and obligation to care for water? To answer this question, I embrace the arguments of the proponents of 'scenario thinking' celebrated by Rickards et al. (2014) to imagine a future that involve placed-based ways of forging subjectivities and social practices. The scenario I offer explores the consequences of more households in capital cities using water tanks as their main source of water for drinking. According to an 
Australian Bureau of Statistics (ABS 2013) report, metropolitan mains water supplies 9I per cent of Australian households drinking water in 2013. It is a story of four parts. First, the narrative mobilises state legislative reform that reimagines water categories and allows households to connect rainwater tanks to plumbing that supplies mains water and thus indoor taps. Second, it acknowledges the use of rainwater tanks to supply drinking water as a long-standing and essential practice in rural and remote Australia. Third, through public education it recognises the debate over the suitability of household rainwater tanks to supply drinking water in capital cities in different states, and concedes that except for suburbs adjacent to industrial emissions, tank rainwater is usually suitable for drinking (enHealth 2004). Fourth, this leads to investment in household water tanks to supply drinking water, alongside other domestic uses. A re-examination of water practices ensues through the embodied knowledge and intimate connections facilitated by the work of tank and roof maintenance, alongside boiling, filtering and storing. The residents' commitment to care for metropolitan mains water is enhanced by an embodied knowledge of the sight and taste of water provisioned for drinking. In this world, the provisioning of drinking water describes a process in which there is a commitment to an understanding of water concerns and commitment to care for water held together not by strict water restrictions but proximity and becoming a carer. People reserve a deep respect and affections for water.

The emerging themes from a socio-technical and embodied analysis of Burmese migrants' drinking water geographies, who have lived with water scarcity, point towards practical contributions that can be made to water sustainability debates by offering questions that open different pathways to defend the inalienable right to potable water. Future household sustainability research that involves minority social groups in a diversity of provisioning household practices is crucial to troubling taken-for-granted practices in the Global North and offering pathways to become differently modern. 


\section{Reference}

Allon, F. \& Sofoulis, Z. (2006) 'Everyday Water: Cultures in Transition', Australian Geographer 37(I) Pp. 45-55.

Anonymous (2009) 'Water problems in Yangon', new mandala, 02 March, available from: http://www.newmandala.org/water-problems-in-yangon/

Australian Bureau of Statistics (ABS) (2016) Migration Australia 20I4-20I5, Canberra, Australian Bureau of Statistics, available from:

http://www.abs.gov.au/ausstats/abs@.nsf/mf/34l2.0/

Australian Bureau of Statistics (ABS) (20I3) 'Environmental Issues: water use and conservation, Mar 2013', available from:

http://www.abs.gov.au/ausstats/abs@.nsf/Lookup/4602.0.55.003main+features3Mar\%2020 I 3

Bakker, K (2004) An uncooperative commodity: privatising water in England and Wales, Oxford University Press, Oxford.

Bijker, W. E. \& Law, J. (1992) Shaping technology/building society: studies in sociotechnical change, MIT Press, Cambridge, Massachusetts

Butler, J. (1993) Bodies that matter: on the discursive limits of sex, Routledge, New York.

Davison, G. (2008) 'Down the Gurgler: Historical Influences on Australian Domestic Water Consumption'. In P.N. Troy (ed.) Troubled Waters, ANU E Press, Canberra, Pp. 37-65.

Dovers, S. (2008) 'Urban water: Policy, institutions and government'. In P.N. Troy (ed.) Troubled Waters, ANU E Press, Canberra, pp.79-98.

enHealth (2004) 'Guidance on the use of rainwater tanks', Australian Government, Department of Health and Ageing, available from:

http://www.health.gov.au/internet/main/publishing.nsf/content/D3E8C00F304I 304BCA257BF 000 IC685A/\$File/env_rainwater.pdf

Falconer Al-Hindi, K. (I997). 'Feminist critical realism: A method for gender and work studies in geography'. In J. P. Jones, H. Nast, \& S. Roberts (eds.) Thresholds in feminist geography: difference, methodology, representations, Rowman and Littlefield, Lantham, MD, pp. I45-164).

Gandy, M. (2002) Concrete and clay. Reworking nature in New York City, MIT Press, Cambridge, MA.

Gibson, C., Farbotko, C., Gill, N., Head, L. \& Waitt, G (2013) Household sustainability: challenges and dilemmas in everyday life, Edward Elgar, Cheltenham, UK.

Gibson-Graham, R. K. \& Roelvink, G. (2009) An economic ethics for the Anthropocene, Antipode, 4I(I) PP. 320-346.

Graham, S., Desai, R., and McFarlane, C. (2013) 'Water wars in Mumbai', Public Culture 25(I) Pp. II5-|4|. 
Hawkins, G. \& Race, K. (20I I)' Bottle water practices: reconfiguring drinking in Bangkok Households', In R Lane and A Gorman-Murray (eds) Material Geographies of Household Sustainability, Ashgate Publishing, Surrey, Pp. II3-I 24.

Head, L. \& Gibson, C. (20I2) Becoming differently modern: geographic contributions to a generative climate politics. Progress in Human Geography 36(6) pp. 699-7I4.

Head, L. \& Muir, P. (2007) 'Changing Cultures of Water in Eastern Australian Backyard Gardens', Social and Cultural Geography 8 pp. 889-906.

Head, L., Farbotko, C., Gibson, C., Gill, N. \& Waitt, G. (20I3) 'Zones of friction, zones of traction: the connected household in climate change and sustainability policy', Australasian Journal of Environmental Management 20 pp. 35I-362

Head, L, Adams, M., McGregor, H V \& Toole, S. (2014) 'Climate change and Australia', Wiley Interdisciplinary Reviews: WIREs Climate Change, 5(2) PP. I75- 197.

Hitchings, R. (20I2) 'People can talk about their practices', Area 44, Pp. 6I-7

Kaïka, M. (2005) City of Flows: Modernity, Nature and the City, Routledge, London.

Klocker, N. \& Head, L. (2013) 'Diversifying Ethnicity in Australia's Population and Environment Debates', Australian Geographer 44(I) Pp. 4I-62.

Lam, S.-P. (1999) 'Predicting intentions to conserve water from the theory of planned behaviour, perceived moral obligation, and perceived water right', Journal of Applied Social Psychology 29 pp. 1058-107I.

Lawrence, K. \& McManus, P. (2008) 'Towards Household Sustainability in Sydney? Impacts of Two Sustainable Lifestyle Workshop Programs on Water Consumption in Existing Homes', Geographical Research 46(3) pp. 314-332.

Leslie, H. \& Potter, R. (2004) Glossary of Building Terms: HB50-2004, Standards Australia, National Committee on Rationalised Building (NCRB), Sydney.

Maller, C. (20II) 'Practices involving energy and water consumption in migrant households', in P. W. Newton (ed.) Urban consumption, CSIRO Publishing, Melbourne, Pp. 237-250.

Moy, C. (2012) 'Rainwater Tank Households: Water Savers or Water Users?', Geographical Research 50(2) Pp. 204-2I6.

New South Wales Government, Department of Health (2017) Rainwater tanks where a public water supply is available - use of, available from:

http://wwwl.health.nsw.gov.au/PDS/pages/doc.aspx?dn=GL2007_009

New South Wales Government, Department of Primary Industries (2017) 'Rainwater', available from: http://www.water.nsw.gov.au/urban-water/recycling-water/rainwater

Plumwood, V. (2007) 'A review of Deborah Bird Rose's Reports from a Wild Country:

Ethics of Decolonisation'. Australian Humanities Review 42, Pp. I-4.

Plumwood, V. (2002) Environmental Culture: The Ecological Crisis of Reason, Routledge, London and New York.

Probyn, E. (2003) 'The Spatial Imperative of Subjectivity', in Anderson, K. (ed.) Handbook of Cultural Geography, Sage, London, Pp. 290-299 
Reckwitz, A. (2002) 'Toward a theory of social practices: a development in culturalist theorizing'. Journal of Social Theory 5(2), pp.243-263.

Rickards, L., Wiseman, J. \& Edwards, T. (2014) 'The problem of fit: scenario planning and climate change adaptation in the public sector'. Environment and Planning C: Government and Policy, 32, 54I-662.

Riley, M. \& Harvey, D. (2007) Talking geography: on oral history and the practice of geography'. Social \& Cultural Geography 8(3) pp. 345-354.

Sakia, H., Kataoka, Y. \& Fukushi, K. (2013) 'Quality of source water and drinking water in urban areas of Myanmar', The Scientific World Journal, $2013(4)$ PP. I-5.

Sedlak, D.L. (2014) Water 4.0: The past, present and future of the world's most vital resource, Yale University Press, New Haven.

Spearritt, P. (2008) 'The water crisis in Southeast Queensland: How desalination turned the region into carbon emission heaven'. In P.N. Troy (ed.) Troubled Waters, ANU E Press, Canberra, pp. 17-36.

Syme, G. (2008) 'Sustainability in urban water future'. In P. N. Tory (ed.) Troubled Waters, ANU E Press, Canberra, pp. 8I-98.

Shove, E. (2003) Comfort, cleanliness and convenience: The social organisation of normality, Berg, Oxford.

Shove, E., Pantzar, M., \& Wilson, M., (2012) The dynamics of social practice: Everyday life and how it changes, Sage, London.

Sofoulis, Z. (20II) 'Skirting complexity: The retarding quest for the average water user', Continuum: Journal of Media \& Cultural Studies, 25(6) pp. 795-8I0.

Sofoulis, Z. (2006) 'Changing water cultures.' In E. Probyn, S.Muecke, and A. Shoemaker (eds.) Creating value: Humanities and their publics, Australian Academy of Humanities, Canberra, Pp. 105-116.

Sofoulis, Z. (2005) 'Big Water, Everyday Water: A Sociotechnical Perspective', Continuum: Journal of Media and Cultural Studies, 19(4) Pp. 445-463.

Tokyo Engineering Consultants, Yachigyo Engineering, Yokohama Water and Metawater (20I4) Water Supply Improvement Project Study for Yangoon City and Pathein City, Final Report, available from:

http://www.mhlw.go.jp/topics/bukyoku/kenkou/suido/jouhou/other/dl/o4_I50324b.pdf

Waitt, G. \& Warren, A. (2008) “'Talking shit over a brew after a good session with your mates”: Surfing, space and masculinity', Australian Geographer 39(3) pp. 353-365.

Waitt, G \& Clifton, D. (20I3) “'Stand out, not-up”: bodyboarders, gendered hierarchies and negotiating the dynamics of pride/shame', Leisure Studies 32 (5), 487-506. 
